\title{
Integrating Mentorship in a Communication Capstone Class to Support the Development of a Community of Practice in the College of Engineering
}

\author{
Debora Rolfes and Julie Hunchak \\ Ron and Jane Graham School of Professional Development, College of Engineering \\ University of Saskatchewan \\ debora.rolfes@usask.ca,julie.hunchak@usask.ca
}

\begin{abstract}
The Certificate in Professional Communication programme at the University of Saskatchewan concludes with a capstone class that requires students to design a mentorship project to solve a communication problem involving junior students. This course was designed to fulfill two objectives. First, the act of mentoring should reinforce the rhetorical theory and practice learned in the previous courses in the programme. Second, the act of mentoring should move the senior students from a position of novice to that of peer within a community of practitioners of effective rhetorical communication. If these two objectives are met, RCM 495 Rhetorical Peer Mentorship enables learning transfer from an academic setting to a professional environment.
\end{abstract}

Keywords: Professional Communication, Rhetoric, Community of Practice, Mentorship

\section{INTRODUCTION}

One of the enduring problems in the field of postsecondary education is how to ensure the transfer of knowledge and skills from the classroom to a professional environment. In fact, teaching for transfer is such a tenacious issue that it can be difficult even to help students transfer knowledge within a single course. Salomon and Perkins share an anecdote about physics students who were unable to transfer their learning of how to calculate the time it takes for a ball to fall from a tower to an analogous problem of a ball falling into a hole [9]. Extensive study of the problem of transfer as it pertains to teaching in the field of communication [3], [6], [9] suggests that teaching for transfer in this field can be an even more significant challenge. The study of communication is less about learning the content of a message and more about learning how to best present any content for a given context. Learning to communicate as a professional involves becoming intimately familiar with genres of communication that must be applied and adjusted contextually, but Freedman and Adam claim that "[e]ven in courses where the instructor is directly simulating a workplace task through a factually based case study, the nature of writing is fundamentally different because of the radical differences between the two rhetorical contexts" [4]. This lack of alignment between the problems (exigencies) that call aaa document into being can make transfer precarious because students do not recognize deeper similarities in the contexts.

A compounding problem for the teachers of communication in professional colleges is that, in these environments, communication is seen as a "soft skill", an ancillary topic, the study of which steals attention from the more important subjects that must be mastered to succeed in the profession. When communication skills are regarded as secondary to the core learning of a programme, students may not invest the time and energy needed to achieve what Saloman and Perkins identify as the high-road mechanism of transfer which "involves the explicit conscious formulation of abstraction in one situation that allows making a connection to another" [9]. In other words, students tend to learn enough about genres of communication to replicate them in given academic contexts, but do not develop the intimate familiarity with communication theory that allows them to abstract principles that they can then apply in professional settings. As argued in Communication Class Size and Professional Identity, this undervaluing of communication skills in professional colleges is particularly prevalent in engineering colleges where many students quickly take on an identity of engineer that embraces the characterization of being a poor communicator [7]. In this environment, persuading students to invest in deep learning of communication skills that will lead to transfer of skills and knowledge to the professional arena is a significant challenge.

This paper briefly describes the communication programme at the Ron and Jane Graham School of Professional Development, College of Engineering (SoPD) at the University of Saskatchewan (U of S) and 
then discusses how the new capstone mentorship class is designed to enhance learning transfer by solidifying in our students a sense of identity as rhetorical communicators.

\section{THE COMMUNICATION PROGRAMME AT THE RON AND JANE GRAHAM SCHOOL OF PROFESSIONAL DEVELOPMENT}

The communication programme offered by the SoPD is based on two pedagogical assumptions. First, learning about how to communicate professionally is best transferred when that learning is based in rhetorical theory that develops a student's judgment. Second, trained judgment will best be retained when it is an integral part of an identity that is claimed by the student. This identity is formed when students learn communication skills as part of a community of practice.

\subsection{Rhetorical Foundation}

Every engineering student at the $\mathrm{U}$ of $\mathrm{S}$ takes Rhetorical Communication (RCM) 300 Effective Professional Communication. This course was designed in response to the perceived need to enhance the communication skills of engineering graduates from the $U$ of S. The theoretical foundation of the course is the discipline of rhetoric because it "provides students with a paradigm and corresponding discourse that enables them to assess the professionalism of others and cultivate their own professionalism" [7]. The study of rhetoric addresses the difficulty that students have transferring knowledge about genres from one context (academic) to another (professional) by focusing less on the formal requirements of the genre (although these standards are learned) and more on the particular needs of both the writer and reader that are being met by that genre. Students develop sensitivity to the contextual determiners of credibility and persuasion and learn to adapt genres to those needs. Ideally this sensitivity becomes a habit of thought that accompanies a student from context to context.

The class size for RCM 300 is limited to 22 students. The learning objectives of the course include higher order learning outcomes, in line with those mandated by the Canadian Engineering Accreditation board (CEAB), of selecting and applying the appropriate skills, concepts, and tools to solve open-ended problems [12]; when the subject matter is communication, these skills can only be practiced and coached in a setting in which every student actually communicates in the classroom. In the RCM 300 classroom, students not only learn about rhetoric, but also apply it in a supportive and reflective environment. This reflection on communication experiences leads to deeper learning: principles of communication are abstracted from specific classroom experiences and made available to transfer to new contexts.

\subsection{Community of Practice}

In addition to the required communication course, the SoPD offers a suite of nine senior level communication classes. These courses maintain the disciplinary foundation of rhetoric while focusing on a specific area of professional communication. Engineering students can take courses in leadership, negotiation, interpersonal communication, public speaking, composition, and document design as electives in their programme, or they can take six of these senior courses to complete a Certificate in Professional Communication (CPC). While deepening students' learning in the field of rhetoric, these courses also serve to achieve the second pedagogical objective of the communication programme by strengthening the community of practice first established in the required communication course (RCM 300). As demonstrated in Situated Professional Communication: A Rhetorical Approach, the SoPD's communication programme seeks to create and reinforce an identity of effective rhetorical practitioner in our students by inviting students to become part of our community of practice [8]. Etienne Wenger defines a community of practice as a group united by joint enterprise, mutual engagement, and shared repertoire [13]. Beginning in RCM 300, students are invited to see themselves as cooperating with their instructor and their peers to develop the critical skills to assess the effectiveness of the communication demonstrated in case studies, in their instructor's communication, and in their own attempts at effective professional communication in the classroom. This engagement with each other's learning and skill deepens as students acquire the shared repertoire of familiarity with rhetorical theory and the mindset that facilitates critical evaluation. Students' membership in the community of rhetorical practitioners is strengthened with each senior communication course. Because class sizes remain small, students interact closely with instructors whose academic research interests and professional practice are founded on the study of rhetoric. Those students who have opted to take the CPC form ties with their peers and develop a community within the college of engineering. These students self-identify as making a conscious choice to add effective communicator to their growing identity of engineer. In formal academic experiences and in non-academic events such as our public speaking competition and social receptions for faculty and students, we reinforce the mutual engagement of all members in our community of rhetorical practitioners. These events provide ongoing opportunities for all members to recognize the joint enterprise of supporting identity formation as effective communicators. 


\section{CAPSTONE CLASS IN RHETORICAL MENTORSHIP}

In 2014, the SoPD piloted a new course that has become the required capstone class for the CPC. RCM 495 Rhetorical Peer Mentorship is analogous to capstone design courses in engineering, in that students work in groups to design a solution to an open-ended problem, calling upon the knowledge and skills learned in the Certificate in Professional Communication programme. Only students who are nearing completion of the CPC are able to register in RCM 495. In the first few weeks of the term, students form project groups of 3-5 members. Each group identifies a communication problem involving junior students within the college and then designs and implements a project in which they will act as mentors working with the junior students to reach a solution. In the first month of class, RCM 495 students give seminar presentations covering theoretical material about mentorship and communities of practice that they will use in the implementation of their projects. At the end of the term, these student mentors write a report and give a presentation in which they describe the problem they identified, the solution they designed, and then assess their success. This course was designed to deepen CPC students' understanding of rhetorical theory and practice as well as to transition senior CPC students from a position of novice to that of peer within the community of practice of rhetorical communicators.

\subsection{Deepening Rhetorical Thinking}

RCM 300 introduces rhetorical theory that forms the foundation of all the subsequent senior level communication classes. Two key theoretical models are Bitzer's description of the rhetorical situation [2] and Aristotle's modes of appeal [1]. These theories guide the student to assess a situation to determine what problem (exigence) needs to be solved, to analyze the audience who will be persuaded to help solve the exigence, and to design a message making maximum use of the credibility of the speaker, the available arguments, and the audience's investment in the situation. Senior communication courses introduce further rhetorical theory, but, in all cases, students are being trained to think of their communication, especially in academic and professional settings, as pragmatic, problem-solving action. The objective is to help students develop the mindset of a rhetorician, to automatically choose to assess a situation to determine how communication can be designed to have a pragmatic effect. Tishman, Jay, and Perkins refer to a mindset as a "thinking disposition." They define thinking dispositions as "comprised of three elements: abilities, sensitivities, and inclinations" [11]. Our students begin to develop the abilities (defined as the capabilities and skills) to think as rhetoricians in RCM 300 where they are introduced to the shared repertoire of the discipline of rhetoric; as they begin to implement those abilities in class assignments, they develop sensitivity: "an alertness to appropriate occasions for exhibiting the behavior" [11]. This sensitivity is deepened through exposure to new appropriate occasions in senior communication courses. The third stage of developing a disposition to think rhetorically is to reinforce the "tendency to actually behave in a certain way" [11]. This third stage is where teaching for transfer becomes difficult. Since all our communication courses are founded on the discipline of rhetoric, students are implicitly and often explicitly cued to approach situations encountered in class assignments from a rhetorical perspective; it can be difficult for students to develop the inclination to automatically frame contexts as involving exigencies calling for a rhetorical solution when the instructor initiates the framing of the situation. RCM 495 Rhetorical Peer Mentorship is designed to help students reinforce their inclination to approach communication issues with a rhetorical mindset by moving them outside of the classroom environment and putting them in a position where they will persuade other students that a particular situation is rhetorical. The problems tackled by groups in RCM 495 involve communication, so, of course, the mentors are inclined to see their role in terms of rhetorical activity. However, because they are mentoring junior students who do not have the same indepth training in rhetoric, the mentors need to explicitly frame this new situation in rhetorical terms for the mentees and, in doing so, reinforce their own inclination to think in those terms.

For example, one group of mentors identified a communication issue in the second-year Mechanical Engineering design class; students in this course are so caught up in the design process that they often leave writing the final design report to the last minute and so do not adequately represent their design in the report. This mentorship group worked with the second-year design course instructor to make themselves available to secondyear design students throughout the term, so that the mentors could help the students recognize points in the design process at which they could be working on material that would be included in the final report. Although the mentored students were taking RCM 300 concurrently with their design class, for the most part, they had not made the transfer of their knowledge from RCM 300 to see that the design report could be a locus of credibility and persuasion filling a need in the design process. The RCM 495 students, by recognizing and articulating the need for a rhetorical mindset in the writing of a second-year design report, were helping the second-year students recognize a rhetorical situation, while reinforcing for themselves the inclination to behave as effective practitioners of rhetoric. In effect, our RCM 
495 mentors model rhetorical problem solving in situations where they have to find the appropriate rhetorical theories to call upon to persuade the students whom they are mentoring that there is a problem, that it involves communication, persuasion, and credibility, and that a rhetorical mindset is part of the solution.

\subsection{Mentoring Within the Community of Practice}

Asking participants in RCM 495 to identify and help solve a rhetorical exigence within the College of Engineering deepens their understanding of how rhetorical theory guides practice in real-world settings. However, that increased comfort with rhetorical theory may not be available for transfer if students do not incorporate it into their identity as a professional. Because the mentorship project must involve other students in the college, RCM 495 invites our mentors to integrate themselves more fully into a community of practice in which they will transition from the position of novice to that of peer-mentor. Etienne Wenger claims that this participation in a community of practice is essential to building an identity that helps incorporate information into meaningful knowledge that is available to transfer to other environments. Wenger suggests that "[w]hen information does not build up into an identity of participation, it remains alien, literal, fragmented, unnegotiable. It is not just that it is disconnected from other pieces of relevant information, but that it fails to translate into a way of being in the world coherent enough to be enacted in practice" [13]. Although all the senior communication courses in the CPC work to deepen a sense of community through the shared interest in developing rhetorical communication skills, that community is rather flat, with essentially two layers of participants: instructors, who are experts in the field, and students, who are novices. RCM 495 takes students out of the classroom and places them in a situation where they become the "experts" in communication and must take responsibility to mentor junior students to a position of proficiency that allows for the exigence to be remediated. Lave and Wenger describe an effective community of practice as involving complex layers of hierarchy, in which experts, newcomers, and those in-between are engaged in the pursuit of common knowledge: "The diversified field of relations among old-timers and newcomers within and across the various cycles, and the importance of near-peers in the circulation of knowledgeable skill, both recommend against assimilating relations of learning to the dyadic form characteristic of conventional learning studies" [5]. The complication of the organization of the community of practice forces mentors into positions of responsibility and authority that encourages abstraction of concepts and transfer of knowledge to a new environment. While the instructors of RCM 495 still occupy the position of expert, they act more in the role of consultant rather than instructor; the mentors identify an exigence and then invite junior students to participate in a project to address that problem. In the seminars, workshops, and informal exchanges designed by the mentors for the mentees, the role of expert shifts as the RCM 495 students become near-peer mentors for the mentees. These mentees are voluntary participants in the project and are engaged novice members of the community of practice. These junior students join the mentors in a shared enterprise to solve an exigence that they all recognize. The shared repertoire of rhetorical theory and practice is developed as the mentors help the mentees explore solutions for the problem. Ideally, mutual engagement develops as both mentors and mentees see that their participation in the project develops everyone's skills. As the mentees are exposed to a pragmatic application of rhetorical theory, the mentors develop confidence in their command of the material learned in the course of the CPC.

One of the readings for RCM 495 concerns the role of mentor, as opposed to instructor, tutor, or marker. Smith comments that the term mentoring "helpfully distinguishes the bulk of peer mentoring activity from authoritative 'teaching' and supervisory roles, while not excluding instructional roles altogether. It acknowledges the informal and social aspects of learning that occur among near-peers" [10]. It is important that both the mentors and mentees understand that they are working together to implement a solution to an exigence; it is this social interaction that Wenger associates with participation that encourages the formation of identity as part of an effective community of practice. Members recognize a joint enterprise towards which they all are working; mutual engagement grows as the mentors introduce the language of rhetorical practitioners to the mentees, and the mentees see the mentors develop their own understanding of that language as it is applied in the project. Ideally, in creating a community of practice that includes expert instructors, near-peer mentors, and newcomer mentees, RCM 495 facilitates a deeper understanding of rhetorical theory and practice by transitioning senior communication students into a role of mentor. In this role, these mentors become more committed members of the broader community of rhetorical practitioners and reinforce their identity as professionals who communicate well. This identity should make their knowledge of rhetorical theory and practice available to transfer to other professional contexts.

\subsection{A Student's Experience of Rhetorical Mentorship}

The RCM 495 course provided my colleagues and me with a unique challenge that gave us the opportunity to expand our rhetorical communication skills and apply them in a new context. Instead of responding to specific 
prompts or submitting regular assignments and papers, this course challenged us to identify an exigence and determine how we could help to solve it through peer mentorship and communities of practice. My group identified the problem that undergraduate students often avoid networking because they are not aware of the potential benefits of networking and have the misconception that the sole purpose of networking is to secure employment. Our group's goal was to serve as mentors for junior RCM students to help them understand networking as building relationships, overcome their fears of networking, and build confidence in their networking skills. Through this project, I came to better appreciate the power of rhetorical communication, the challenge of creating and cultivating a community of practice, and the value of reframing and growing personal identity.

It was clear that our team needed to draw on rhetorical theory to fulfill the RCM 495 course requirements, but I also came to appreciate how useful the rhetorical theory, which we had applied academically only in classroom settings, was for developing and implementing a successful project. Our group understood from Bitzer that we needed to confirm the facts and generate related audience interest to engage our audience with our project. Accordingly, we surveyed our audience (four classes of RCM 300 students) to determine whether our exigence was valid and to gauge their interest in remedying that exigence. This initial survey prompted our audience - our mentees - with questions about their understanding of networking, their fears associated with networking, their networking strengths, and which networking skills they would like to improve. We made it clear that we would use their initial survey responses to guide the direction of our project so that it would be of maximum benefit for them. The purpose of involving our audience in the design of our project through this initial survey was to build a "mutuality of engagement" [13] with our mentees as defined by Wenger. Through this engagement, we could respond to our mentees' needs and they could influence the direction of our project so we could "establish relationships in which this mutuality [was] the basis for an identity of participation" [13]. From this initial survey, we learned that the majority our mentees saw networking as a way to secure employment in their industries of interest, were afraid of awkward silences and looking foolish, and wanted to improve their ability to start conversations.

We used this initial classroom survey to help us analyze our audience and ensure that we tailored our project to their needs so they would be interested in participating. Through the survey, we were able to identify and share common fears of and interests in networking in a second classroom visit. Our team designed a Tips \& Strategies handout to share in the second classroom visit with our mentees where we addressed their responses to the initial survey, provided more evidence for the exigence that students avoid networking, and introduced our networking event as a remedy for this exigence. This second classroom visit was geared towards building our group's credibility in the eyes of our mentees by demonstrating how we incorporated the needs and interests they shared in the initial surveys into the focus of our project. Through this second visit to RCM 300 classrooms, we wanted to develop "a coherent community of discourse [to support] the values and skills we want[ed] our [mentees] to take away" [3]. We shared some of our personal experiences of networking blunders and successes to demonstrate our desire to learn more about networking through this project and work with our mentees to improve our skills together. We shared our research into scientific studies to validate fears of networking and to help our mentees realize they were not alone in fears of networking. We also shared some tips and strategies to give our mentees tools to begin to overcome their networking fears. We introduced our networking event as a practical opportunity for mentees to join us in practicing networking skills and building relationships with the eight industry and university guests we invited. This event was designed to be a fun, lowpressure introduction to networking for our mentees to start developing "mental habits, or dispositions, that [would] enable them to use that expertise in new situations" [3].

The highlight of our project was the networking event we hosted because, with the theme of starting conversations, this event brought students, industry guests, university guests, and our group together in a relaxed environment that fostered relationship-building networking practice. Because of our RCM training, our team was very aware that as peer mentors it was crucial for us to demonstrate our credibility but also be relatable peers to our mentees. To develop common ground with our mentees, we made it clear that we were not expert networkers and invited eight industry and university guests to help all of us students to learn more about networking and to practice our skills. By providing some expertise in class and then facilitating a networking event with experienced guests we established "relationships of trust, shared knowledge and mutual engagement" [10] with the mentees who attended the networking event.

We designed our networking event with the needs of our mentees in mind: they wanted to practice starting conversations, so we developed a series of prompting topics and questions that could help start a variety of conversations, to ensure that the evening was not just a series of self-introductions. We hoped that our mentees and guests could lean in to these topics and questions so they could enjoy a variety of conversations (from discussing networking fears, to memorable successes and failures, to funny things that happened at school or work) without having to worry about what to talk about next. We deliberately structured the evening so that four groups 
of students (with one of our group members in each student grouping) would rotate through four pairs of guests twice throughout the evening. This group rotation allowed everyone to meet and converse with everyone in the room, and each of our group members could work more closely with the mentees in this smaller group setting. Although our group was aware that "many studies in learning transfer emphasize long-term pedagogical experiences" [3] as the best way to build skills that will enable students to better handle new scenarios, our schedules and the course timeline were not conducive to a long-term experience. Instead, we poured our energy into this networking event hoping that it would encourage our mentees to seek out future networking opportunities and to engage with the mindset of relationship building. By participating alongside our mentees and guests we could foster a community of practice to benefit everyone involved.

To evaluate our project and determine whether the rhetorical theories we drew on helped us to successfully remedy our exigence, our group followed up with our mentees and guests after the networking event with a brief survey to get their feedback. The response was overwhelmingly positive from mentees and guests alike. Even though we only had two classroom visits and one evening event with the mentees, I was thrilled to see a noticeable shift in their perception of networking from their follow-up survey responses. The mentees shared that after our event they viewed networking in a more positive light and felt more comfortable with the idea of networking. The students also shared that they came to understand the importance of relationship building in networking and appreciated that we had used their initial survey responses to ensure the event would be worth their while. Other comments included the realization that networking can be fun and that it was interesting to hear perspectives from guests and students of diverse backgrounds. This follow-up survey confirmed that our group succeeded in shifting our mentees' mindsets about networking from a job-focused to a relationship-focused approach and helped them to become more comfortable with conversing in a networking situation. I think we also succeeded in helping our mentees to realize that they are capable of meeting and conversing with new people to find common ground and build relationships; we helped them to identify as stronger communicators and more confident individuals.

Over the course of my term as a student in the RCM 495 class and as a mentor in the networking group project, I gained a new perspective on my "RCM toolbox" developed through the CPC and a new confidence in my skills as an effective professional communicator. The fact that our professors trusted us with the task of designing and implementing our own projects outside of the classroom gave me a new level of confidence as I realized that I was equal to the challenge. The success of my group's networking project stemmed from our roots in rhetorical theory and clarified for me that I am a skilled communicator who can learn from and adapt to real-time situations outside of the classroom. I think that through this RCM 495 course Wenger's claim about communities of practice rings true in that "some of their greatest value lies in intangible outcomes, such as the relationships they build among people, the sense of belonging they create, the spirit of inquiry they generate, and the professional confidence and identity they confer to their members" [14]. During this project, I applied my knowledge of rhetorical theory outside of the classroom to help remedy the exigence that students often avoid networking and misunderstand it as only a method of securing a job. To implement this project with my group, I drew on my own network of industry and university members and engaged with them to involve them in our project, I interacted with junior students and exchanged stories and experiences with them to help each other learn, and I grew into confidence in my communication skills - a confidence I do not think I would have attained in a strictly classroom setting. This networking project in RCM 495 empowered me to have confidence in my communication skills, encouraged me to continue learning about communication, and inspired me to realize that my rhetorical communication skills have become a crucial part of who I am and what I will bring to all of my future endeavours.

\section{CONCLUSION}

Although mentorship programmes are often instituted for the benefit of the mentees, RCM 495 was developed specifically to enhance the learning of the mentoring students. The course has been offered four times since 2014; anecdotal evidence suggests the experience of designing and implementing a solution to a communication problem involving junior students can have the desired outcome of reinforcing senior students' understanding of the theory and practice of rhetoric while moving them from a position of novice to that of peer within a community of practice of rhetorical practitioners. This shift helps affirm for the students an identity in which effective communication is a central characteristic and which, therefore, makes their learning more available for transfer to professional settings.

There are, however, some lessons learned from reflecting on students' experience in the course. First, in order to attract junior students to mentor, the project groups must identify an exigence that is, to some degree at least, already apparent to the potential mentees. Given the short timeline of a single term and the full schedules of students, project groups do not have time to spend convincing junior students of a problem's existence. Second, establishing a sense of community early is vital to encourage ongoing participation from mentees. Even 
when mentees see that a mentorship project offers a solution to a problem that they recognize, other pressures will distract them from participation. However, when junior students feel that they are part of a community, that sense of support (and perhaps even obligation) can help encourage ongoing commitment to the project.

\section{Acknowledgements}

The authors would like to thank the Gwenna Moss Centre for Teaching and Learning for providing funding for the Graham School of Professional Development SoTL Cluster. In addition, the authors thank the students in the winter 2017 section of RCM 495 for their thoughtful feedback.

\section{References}

[1] Aristotle, The Rhetoric. Friedrich Solmsen (ed.), W. Rys Roberts (trans.). New York: Random House, 1954, 289 pp.

[2] Lloyd F. Bitzer, "Functional communication: a situational perspective," Rhetoric in transition: studies in the nature of uses of rhetoric. Eugene E. White (ed.). University Park: The Pennsylvanian State University Press, 1980, pp. 21-38.

[3] Doug Brent, "Transfer transformation, and rhetorical knowledge: insights from transfer theory," Journal of Business and Technical Communication, vol. 25, no. 4, pp. 396-420, 2011.

[4] Aviva Freedman and Christine Adam, "Learning to write professionally: 'Situated Learning' and the transition from university to professional discourse," Journal of Business and Technical Communication, vol. 10, no. 4, pp. 395427, 1996.

[5] Jean Lave and Etienne Wenger. Situated Learning: Legitimate Peripheral Participation. Cambridge: Cambridge University Press, 1991, 138 pp. \{ISBN 978-0-521-42374-8\}

[6] Carolyn Miller, "Genre as social action," Quarterly Journal of Speech, vol. 70, pp. 151-167.

[7] Corey Owen and Debora Rolfes. "Communication class size and professional identity." age 26: 1.

[8] Corey Owen, and Debora Rolfes. "Situated professional communication: a rhetorical approach," in Proceedings of the Canadian Engineering Education Association, (Canmore, AB; 8-11 June 2014), 3 pp., 2014.

[9] Gavriel Salomon and David N. Perkins, "Rocky roads to transfer: mechanisms of a neglected phenomenon," Educational Psychologist, vol. 24, no. 2, pp. 113-142, 1989.

[10] Tania S. Smith, "Defining features of curricular peer mentoring programs," in Undergraduate Curricular Peer Mentoring Programs: Perspectives on Innovation by
Faculty, Staff, and Students. Tania S Smith (ed.), Blue Ridge Summit, PA: Lexington Books, 2012. \{ISBN 9780739179338\}

[11] Shari Tishman, Eileen Jay, and David N. Perkins, "Teaching thinking dispositions: from transmission to enculturation," Theory into Practice, vol.32, summer, pp. 147-153, 1993.

[12] University of Saskatchewan. College of engineering communication rubric. 2014.

[13] Etienne Wenger, Communities of Practice: Learning, Meaning, and Identity, Cambridge: Cambridge UP, 1998, 318 pp. \{ISBN: 978-0-521-66363-2\}

[14] Etienne Wenger, Richard McDermott, and William M. Snyder, Cultivating Communities of Practice: A Guide to Managing Knowledge. Boston: Harvard Business School Press, 2002, 284 pp. \{978-1-57851-330-7\}

CEEA17; Paper 114 